\title{
A National Survey on the Environment and Basic Techniques of Endoscopic Retrograde Cholangiopancreatography in Korea
}

\author{
Jae Min Lee ${ }^{1}$, Sung Hoon Moon², Sang Wook Park³, Woo Hyun Paik', Chang Nyol Paik', Byoung Kwan Son ${ }^{6}$, \\ Tae Jun Song ${ }^{7}$, Dong Won Ahn', Eaum Seok Lee ${ }^{9}$, Yun Nah Lee ${ }^{10}$, Yoon Suk Lee ${ }^{11}$, Tae Joo Jeon ${ }^{12}$, Hyung Ku Chon ${ }^{13}$, \\ Dong Wook Lee ${ }^{14}$, Chang Hwan Park ${ }^{15}$, and Kwang Bum Cho ${ }^{16}$, Committee of Policy-Quality Management, \\ Korean Pancreatobiliary Association \\ ${ }^{1}$ Department of Internal Medicine, Korea University College of Medicine, Seoul, ${ }^{2}$ Department of Internal Medicine, Hallym University \\ College of Medicine, Anyang, ${ }^{3}$ Department of Internal Medicine, Kwangju Christian Hospital, Gwangju, ${ }^{4}$ Department of Internal \\ Medicine, Seoul National University College of Medicine, ${ }^{5}$ Department of Internal Medicine, College of Medicine, The Catholic \\ University of Korea, ${ }^{6}$ Department of Internal Medicine, Eulji University College of Medicine, ${ }^{7}$ Department of Internal Medicine, \\ University of Ulsan College of Medicine, ${ }^{8}$ Department of Internal Medicine, Seoul National University Boramae Medical Center, Seoul, \\ ${ }^{9}$ Department of Internal Medicine, Chungnam National University College of Medicine, Daejeon, ${ }^{10}$ Department of Internal Medicine, \\ Soonchunhyang University School of Medicine, Bucheon, ${ }^{11}$ Department of Internal Medicine, Ilsan Paik Hospital, Inje University \\ College of Medicine, Goyang, ${ }^{12}$ Department of Internal Medicine, Sanggye Paik Hospital, Inje University College of Medicine, Seoul, \\ ${ }^{13}$ Department of Internal Medicine, Wonkwang University School of Medicine, Iksan, ${ }^{14}$ Department of Internal Medicine, Catholic \\ University of Daegu School of Medicine, Daegu, ${ }^{15}$ Department of Internal Medicine, Chonnam National University Medical School, \\ Gwangju, and ${ }^{16}$ Department of Internal Medicine, Dongsan Medical Center, Keimyung University School of Medicine, Daegu, Korea
}

See editorial on page 795.

\section{Article Info}

Received November 7, 2020

Revised December 23, 2020

Accepted January 11, 2021

\section{Corresponding Author}

Chang Hwan Park

ORCID https://orcid.org/0000-0002-2995-8779

E-mail p1052ccy@hanmail.net

Kwang Bum Cho

ORCID https://orcid.org/0000-0003-2203-102X

E-mail chokb@dsmc.or.kr
Background/Aims: The work environment in which endoscopic retrograde cholangiopancreatography $(E R C P)$ is conducted has influence on its efficacy and safety. We aimed to assess the current status of ERCP work environments and to investigate the trends associated with the basic techniques of ERCP in Korea.

Methods: The work environment and information on the basic techniques of ERCP were acquired by the Korean Pancreatobiliary Association (KPBA) through a national survey in 2019. The survey was performed at the KPBA conference in 2019. The contents of survey comprised of the current environment of ERCP, preparation before ERCP, and the preferred basic techniques used in ERCP.

Results: Completed questionnaires were returned from 84 KPBA members. The mean ERCP volume per year was approximately 500 . About $60 \%$ (50/84) reported that they worked with a dedicated ERCP team with experienced nurses. Two-thirds $(57 / 84,68 \%)$ answered that they had a fluoroscopy room used solely for ERCP procedures. All respondents intravenously hydrated the patient to prevent post-ERCP pancreatitis (84/84, 100\%). The preferred procedural sedations were balanced propofol sedation (50\%) and midazolam-only sedation (47\%). Wire-guided cannulation was most commonly used for selective cannulation (81\%). Endoscopic retrograde biliary drainage was preferred over endoscopic nasobiliary drainage (60\% vs $22 \%)$. The initial method of ampullary intervention was endoscopic sphincterotomy in $60 \%$.

Conclusions: Data from the survey involving a large number of Korean ERCP doctors revealed considerable variabilities with regard to the work environment and basic techniques of ERCP in Korea. The study provides information regarding the current trends of ERCP that can be used to establish ERCP standards in Korea. (Gut Liver 2021;15:904-911)

Key Words: Endoscopic retrograde cholangiopancreatography; Current status; Survey

\section{INTRODUCTION}

Since the introduction of endoscopic retrograde chol- angiopancreatography (ERCP) in the $1968,{ }^{1}$ it has been one of the most important procedures to treat biliary and pancreatic diseases. ERCP demands a long procedure time 
and requires substantial training with the considerable risk of complications. ${ }^{2}$ The total volume of its practice has increased significantly the recent years in Korea. ${ }^{3}$ According to a previous study with a Health Insurance Review and Assessment data in Korea, the number of patients who underwent ERCP was 47,027 in 2017, and the annual ERCP rate was reported to be approximately 91 per 100,000 in 2017. ${ }^{4}$ However, the number of studies about the current status and trend of ERCP at a national scale in Korea are lacking.

The environment of endoscopy includes the factors such as endoscopy room, medical professionals, and preparation for endoscopic procedure. Although the overall environment of ERCP is similar to that of esophagogastroduodenoscopy or colonoscopy, it differs with regard to the number of required additional assistants and the need for a radiology technician. The dedicated room and medical professionals for ERCP are important factors that may affect the results. The patient's position and mode of anesthesia or sedation can ensure an easier and better outcome. Moreover, the ERCP procedure and the techniques associated with the cannulation and stone removal must considerably influence the outcomes. ${ }^{5}$ Since technical variations must be associated with differences in quality and safety, it is important to consider these parameters in practice.

Current status of ERCP related with specific issues had been published in Japan. ${ }^{6,7}$ There was a study regarding the Korean trend of ERCP based on publicly open Health Insurance Review and Assessment data. ${ }^{4}$ Recently, a national survey by Korean investigators had been conducted to investigate the ERCP practices and outcomes. ${ }^{8}$ However, it did not identify the current trends of basic ERCP procedures or present a detailed information on its operational setup in Korea.

We conducted a national survey about ERCP, which focused on basic techniques and the associated operational setups. This study is aimed to assess the current trend of ERCP in Korea.

\section{MATERIALS AND METHODS}

\section{Conduct of the survey}

This study was designed as a national survey. It was organized by the committee of policy and quality management in Korean Pancreatobiliary Association. The committee members accumulated the important issues associated with ERCP and constructed key questions about the basic techniques for the same. The questionnaires were prepared and revised by the committee of policy and quality management, and finally constructed in 2019. The survey was performed through a papered questionnaire (Supplementary Material) for participants in Annual Congress of Korean Pancreatobiliary Association 2019 in Korea. Additionally, an online survey with same questions was released for Korean Pancreatobiliary Association members who were unable to attend the congress. It consisted of 36 questions and the contents were classified into three categories: (1) the current environment of ERCP; (2) the preparation for ERCP; and (3) the current trend of basic techniques for ERCP in Korea. The questionnaire was considered valid if all of the required information was provided.

\section{Statistical analysis}

All continuous variables were presented as mean \pm standard deviations. Categorical variables were presented as numbers or proportions. Data were analyzed using the Statistical Package for the Social Sciences version 24.0 (IBM Corp., Armonk, NY, USA).

\section{RESULTS}

A total of 84 completed questionnaires were collected. The mean age of answered ERCP doctors was $46.9 \pm 7.7$ years. There were 80 male doctors and four female doctors. In total, $59 \%$ of doctors had an experience of over 11 years and $41 \%$ of doctors had performed ERCP for more than 5,000 cases.

\section{The environment for ERCP procedure}

Fig. 1 shows the results pertaining to the doctors' experience and ERCP volume. With regard to the number of ERCP procedures performed per week, $41 \%$ of doctors performed the procedure for 5 to 10 cases, and 30\% performed for 11 to 20 cases. In total, $16 \%$ of doctors performed over 20 cases per week. However, $60 \%$ of doctors answered that they had a dedicated ERCP team with experienced nurses, and $40 \%$ of doctors performed ERCP with endoscopy nurses (Fig. 2A). In total, 68\% of doctors reported the presence of a fluoroscopy room dedicated for ERCP in the endoscopy or radiology intervention unit (Fig. 2B). Emergency ERCP was available in $69 \%$, regardless of a weekend or a holiday.

\section{The preparation of ERCP}

Whereas $50 \%$ of ERCP doctors used a balanced propofol sedation for procedural sedation for ERCP, $47 \%$ of ERCP doctors preferred to use midazolam only for procedural sedation (Fig. 3). Only 1\% of the doctors performed the procedure using general anesthesia in Korea. Table 1 presents the preference of patient position and premedi- 
A B

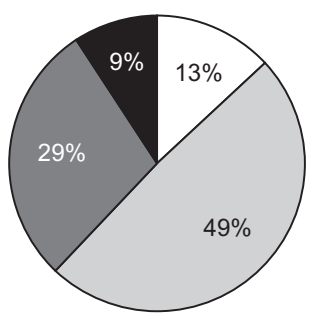

Age (yr)

$\square<30 \square \begin{aligned} & 40-49 \\ & 30-39 \square 50\end{aligned}$
B

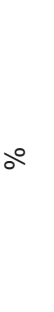

C

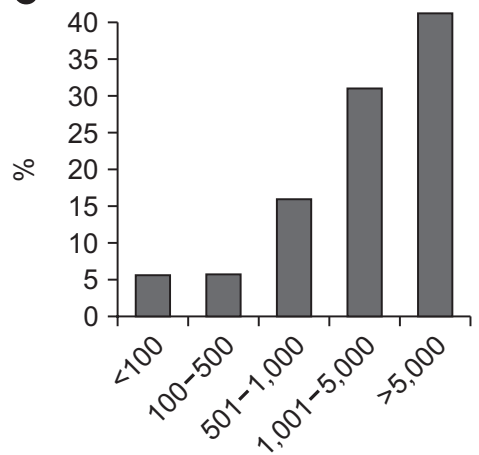

Doctor's total number of ERCP
D

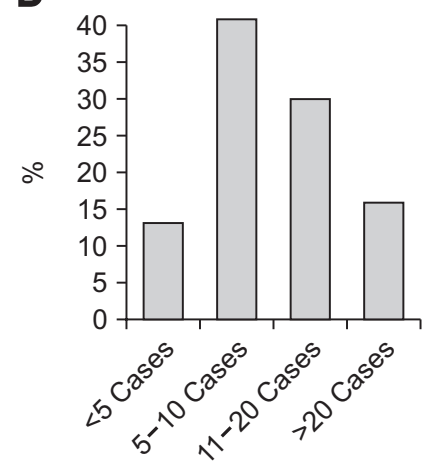

ERCP procedure volume per week

Fig. 1. Endoscopic retrograde cholangiopancreatography (ERCP) experience of Korean doctors and their current ERCP volume. (A) Age, (B) ERCP experience, (C) total number of ERCP, (D) current ERCP volume.

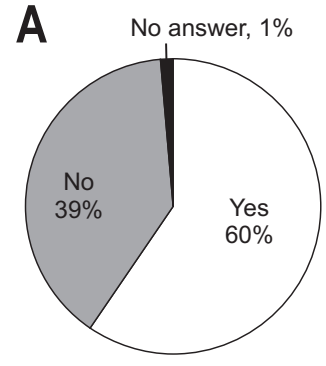

Presence of dedicated ERCP nurse

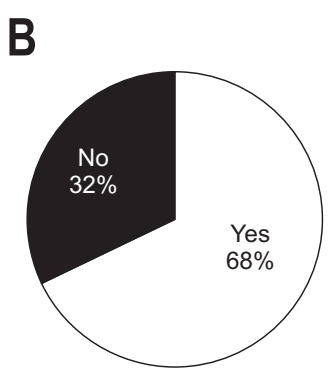

Presence of dedicated fluoroscopy room for ERCP

Fig. 2. Specialized nurse staff $(A)$ and designated unit for endoscopic retrograde cholangiopancreatography (ERCP) (B).

A

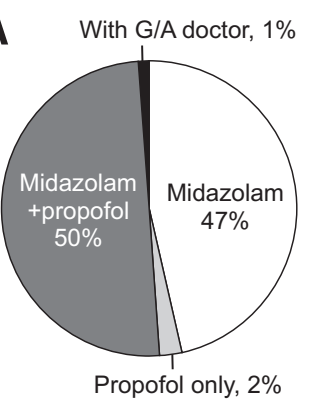

Procedural sedation for ERCP

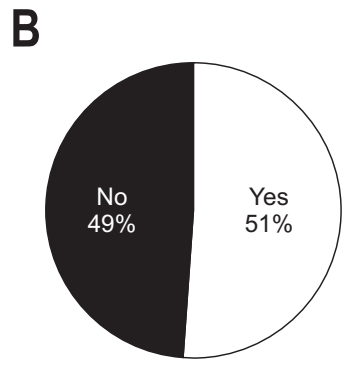

Use of restriction device for ERCP

Fig. 3. (A, B) Preferred method of procedural sedation for ERCP in Korea.

ERCP, endoscopic retrograde cholangiopancreatography; G/A, general anesthesia.

cation. Most doctors preferred the prone position. The number of positive answers was 80 (95\%) for prophylactic use of opioid drug, $68(80 \%)$ for prophylactic use of antiperistaltic agent, and $50(60 \%)$ regarding the use of prophylactic antibiotics before diagnostic ERCP. While 51\% of the doctors routinely use a restriction device for patient's

Table 1. Patient's Position and Prophylactic Treatment for ERCP

\begin{tabular}{lc}
\multicolumn{1}{c}{ Variable } & No. $(\%)$ \\
\hline No. of ERCP doctor & 84 \\
Patient's position for ERCP & $77(92)$ \\
Prone position & $4(5)$ \\
Left lateral position & $3(3)$ \\
Position change as prone after duodenal approach & \\
Use of restriction device & $43(51)$ \\
Yes & $41(49)$ \\
No & \\
Use of opioid analgesics & $72(86)$ \\
Meperidine & $8(9)$ \\
Fentanyl & $4(5)$ \\
None & \\
Use of antiperistaltic agent & $67(80)$ \\
Yes & $17(20)$ \\
No & \\
Use of prophylactic antibiotics & $50(60)$ \\
Yes & $34(40)$ \\
No
\end{tabular}

ERCP, endoscopic retrograde cholangiopancreatography.

position in ERCP, $49 \%$ did not use it. Sixteen percent of ERCP doctors answered that they routinely conducted endoscopic ultrasonography before therapeutic ERCP. In the questionnaire about prevention methods against postERCP pancreatitis (multiple choices are available), most ERCP doctors answered that they usually used the combination of techniques by intravenous hydration, intravenous protease inhibitor and pancreatic stenting against postERCP pancreatitis (Table 2). Table 2 shows data about preparation for ERCP and management after procedure.

\section{The preferred basic technique of ERCP}

Table 3 presents the current trend of prepared device and technique for ERCP in Korea. Regarding selective deep cannulation, $46 \%$ of doctors preferred to use sphinctero- 
Table 2. Preparation for ERCP and Management after Procedure

\begin{tabular}{|c|c|}
\hline Variable & Value \\
\hline No. of ERCP doctor & 84 \\
\hline \multicolumn{2}{|c|}{ Routine diagnostic EUS before therapeutic ERCP } \\
\hline Yes & 13 \\
\hline No & 70 \\
\hline No answer & 1 \\
\hline \multicolumn{2}{|c|}{ Routine follow-up ERCP after successful ERCP } \\
\hline Yes & 3 \\
\hline No & 80 \\
\hline No answer & 1 \\
\hline \multicolumn{2}{|l|}{ Performing urgent ERCP* } \\
\hline Yes & 58 \\
\hline No & 24 \\
\hline No answer & 2 \\
\hline \multicolumn{2}{|c|}{ Prevention against post-ERCP pancreatitis $^{\dagger}$} \\
\hline Intravenous hydration over $1 \mathrm{~L}$ fluid & 52 \\
\hline Intravenous protease inhibitor & 64 \\
\hline Oral protease inhibitor & 5 \\
\hline Pancreatic stenting & 53 \\
\hline Others & 2 \\
\hline \multicolumn{2}{|l|}{ Timing to permit a diet after ERCP } \\
\hline 4-6 Hours & 14 \\
\hline 6-12 Hours & 22 \\
\hline$>12$ Hours & 47 \\
\hline No answer & 1 \\
\hline \multicolumn{2}{|l|}{ First diet on the day after ERCP } \\
\hline Water only & 27 \\
\hline Liquid diet & 17 \\
\hline Soft diet & 12 \\
\hline Regular diet & 5 \\
\hline NPO on the day & 23 \\
\hline
\end{tabular}

ERCP, endoscopic retrograde cholangiopancreatography; EUS, endoscopic ultrasonography; NPO, nil per os.

*ERCP as urgent treatment at night or over the weekend; ${ }^{\dagger}$ Multiple choices are available.

tome and guidewire, but $35 \%$ preferred using a cannulation catheter. Additionally, 19\% preferred to use a contrast agent than a guidewire. There were differences with regard to the basic accessories used in the procedure. A 0.035 -inch guidewire with a straight tip was used by $42 \%$. But $28 \%$ chose a 0.025 -inch angled guidewire, and $23 \%$ preferred a thin straight guidewire. The device used to crush a large stone were as follows; Trapezoid ${ }^{\mathrm{TM}}$ basket (Boston Scientific, Marlborough, MA, USA), 55\%; Power-Catch basket (MTW, Wesel, Germany), 24\%; BML lithotripsy basket (Olympus, Tokyo, Japan), 16\%; and Fusion ${ }^{\circ}$ lithotripsy extraction basket (Cook Medical, Bloomington, IN, USA), $3 \%$. Endoscopic sphincterotomy was more dominantly used than the endoscopic papillary balloon dilation for papilla dilatation in patients with naïve ampulla (Fig. 4A). The preferred methods for biliary drainage included endoscopic retrograde biliary drainage in $60 \%$, endoscopic retrograde nasobiliary drainage in $22 \%$, and both methods
Table 3. Current Status of Prepared Devices and Techniques Used in ERCP

\begin{tabular}{|c|c|}
\hline Variable & No. $(\%)$ \\
\hline No. of ERCP doctor & 84 \\
\hline \multicolumn{2}{|l|}{ Device for selective cannulation } \\
\hline Sphincterotome & 44 (52) \\
\hline Cannulation catheter & 40 (48) \\
\hline \multicolumn{2}{|l|}{ Initial check-up for bile duct cannulation } \\
\hline Guidewire & $68(81)$ \\
\hline Contrast & 16 (19) \\
\hline \multicolumn{2}{|l|}{ Favorite cannulation technique } \\
\hline Sphincterotome+guidewire & $39(46)$ \\
\hline Cannulation catheter+guidewire & 29 (35) \\
\hline Sphincterotome+contrast & $5(6)$ \\
\hline Cannulation catheter+contrast & $11(13)$ \\
\hline \multicolumn{2}{|l|}{ Type of guidewire } \\
\hline Straight tip with 0.035 -inch diameter & $35(42)$ \\
\hline Angled tip with 0.035 -inch diameter & 4 (5) \\
\hline Straight tip with 0.025 -inch diameter & 19 (23) \\
\hline Angled tip with 0.025 -inch diameter & $24(28)$ \\
\hline Others & $2(2)$ \\
\hline \multicolumn{2}{|l|}{ Product for mechanical lithotripsy in ERCP } \\
\hline BML lithotripsy basket (Olympus) & 14 \\
\hline Fusion ${ }^{\circledR}$ Lithotripsy basket (Cook Medical) & 2 \\
\hline Trapezoid $^{\mathrm{TM}}$ (Boston Scientific) & 46 \\
\hline MTW Basket (MTW) & 20 \\
\hline Others & 2 \\
\hline
\end{tabular}

ERCP, endoscopic retrograde cholangiopancreatography.

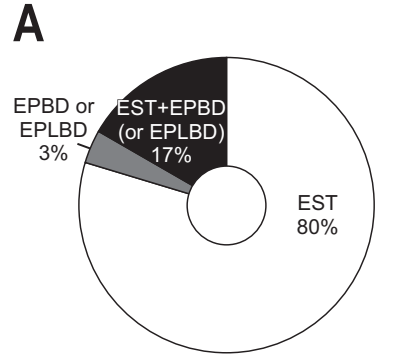

Preferred procedure for opening of naïve ampulla

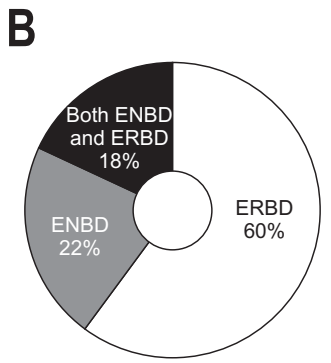

Preferred procedure for biliary drainage therapy
Fig. 4. Preferred basic technique for ERCP. (A) Basic procedure for opening of the naiive ampulla. (B) Basic procedure for bile drainage. ERCP, endoscopic retrograde cholangiopancreatography; EPBD, endoscopic papillary balloon dilatation; EPLBD, endoscopic papillary large balloon dilatation; EST, endoscopic sphincterotomy; ENBD, endoscopic nasobiliary drainage; ERBD, endoscopic retrograde biliary drainage.

at simultaneously in $18 \%$ (Fig. 4B). The mostly preferred salvage technique was wire assisted technique and double guidewire technique. 
Table 4. Comparison of ERCP Procedure by Experience

\begin{tabular}{|c|c|c|c|}
\hline Variable & $\begin{array}{c}<5 \\
\text { Years }\end{array}$ & $\begin{array}{l}5-10 \\
\text { Years }\end{array}$ & $\begin{array}{l}>10 \\
\text { Years }\end{array}$ \\
\hline No. of ERCP doctor & 23 & 11 & 50 \\
\hline \multicolumn{4}{|l|}{ Preparation for ERCP, №. (\%) } \\
\hline \multicolumn{4}{|l|}{ Patient's position } \\
\hline Prone position & $22(96)$ & $11(100)$ & $44(88)$ \\
\hline Left lateral or changing position & $1(4)$ & 0 & $6(12)$ \\
\hline \multicolumn{4}{|l|}{ Use of antiperistaltic agent } \\
\hline Yes & $20(87)$ & $10(91)$ & $37(74)$ \\
\hline No & $3(13)$ & 1 (9) & $13(26)$ \\
\hline \multicolumn{4}{|l|}{ Use of prophylactic antibiotics } \\
\hline Yes & 13 (57) & $8(73)$ & $29(58)$ \\
\hline No & $10(43)$ & $3(27)$ & $21(42)$ \\
\hline \multicolumn{4}{|c|}{ Preferred technique \& device for ERCP, No. $(\%)$} \\
\hline \multicolumn{4}{|l|}{ Cannulation technique } \\
\hline Sphincterotome+guidewire & 9 (39) & 8 (73) & $22(44)$ \\
\hline Cannulation catheter+guidewire & $10(43)$ & $3(27)$ & $16(32)$ \\
\hline Sphincterotome+contrast & 0 & 0 & $5(10)$ \\
\hline Cannulation catheter+contrast & $4(17)$ & 0 & $7(14)$ \\
\hline \multicolumn{4}{|l|}{ Type of guidewire } \\
\hline Straight tip/0.035-inch diameter & $7(30)$ & $1(9)$ & $11(22)$ \\
\hline Angled tip/0.035-inch diameter & 8 (35) & $6(55)$ & $22(44)$ \\
\hline Straight tip/0.025-inch diameter & $7(30)$ & $4(36)$ & $12(24)$ \\
\hline Angled tip/0.025-inch diameter & $1(4)$ & 0 & $3(6)$ \\
\hline Others & & & $2(4)$ \\
\hline \multicolumn{4}{|l|}{ Opening of naïve ampulla } \\
\hline EST & $20(87)$ & $10(91)$ & $37(74)$ \\
\hline EPBD (or EPLBD) & 0 & 0 & $3(6)$ \\
\hline EST+EPBD (or EPLBD) & $3(13)$ & $1(9)$ & $10(20)$ \\
\hline \multicolumn{4}{|l|}{ Biliary drainage therapy } \\
\hline ERBD & $14(61)$ & $10(91)$ & $26(52)$ \\
\hline ENBD & $6(26)$ & 0 & $12(24)$ \\
\hline ERBD+ENBD & $3(13)$ & $1(9)$ & $11(22)$ \\
\hline \multicolumn{4}{|l|}{ Device for small CBD stone } \\
\hline 4-Wired basket & $11(48)$ & $2(18)$ & $26(52)$ \\
\hline 8-Wired basket & $7(30)$ & $5(45)$ & $13(26)$ \\
\hline Retrieval balloon & $5(22)$ & $4(36)$ & $11(22)$ \\
\hline
\end{tabular}

ERCP, endoscopic retrograde cholangiopancreatography; EST, endoscopic sphincterotomy; EPBD, endoscopic papillary balloon dilatation; EPLBD, endoscopic papillary large balloon dilatation; ENBD, endoscopic nasobiliary drainage; ERBD, endoscopic retrograde biliary drainage; $C B D$, common bile duct.

\section{The difference of ERCP procedure between groups by experience}

Table 4 shows the difference of preparation, basic procedure and preferred device for ERCP between three groups by doctor's experience in Korea. There were no significant differences in each group by their experiences.

\section{DISCUSSION}

This study is a national survey regarding ERCP operational environment and basic ERCP technique trends in
Korea. The result was primarily collected from well-experienced ERCP doctors. Most Korean ERCP doctors in this survey perform over five cases requiring ERCP procedures per week, with an overall experience of more than 10 years. Therefore, the trend in the survey represents highly active endoscopists. Notably, the status of ERCP in Korea showed that it somewhat differed from that in other countries.

The staff required for the ERCP procedure typically include minimum of one physician, two assistants, and a radiology technician. ${ }^{9}$ It is recommended to have a fluoroscopy room for endoscopic procedure, specifically in medical centers that perform over 600 ERCP annually. ${ }^{10}$ The quality of Korean ERCP doctors showed to be in a well-controlled state. However, the lack of specialized ERCP nurses and appropriate systems for emergency ERCP are often noted. In other countries, $40 \%$ of endoscopists perform fewer than 50 sphincterotomies in Canada, ${ }^{11}$ and a large number of ERCPs tend to be performed in low volume centers in America and United Kingdom. ${ }^{12,13}$ According to the national data obtained from Health Insurance Review and Assessment Service, ERCP is mostly performed in university hospitals or tertiary care institutions. ${ }^{8}$ Our survey in Korea revealed that a large number of ERCPs were performed by small number of well-experienced ERCP doctors. We found that ERCP procedures in Korea had a tendency to be concentrated on doctors in university hospitals or tertiary referral centers.

There are some differences of ERCP preparation in Korea compared with other Western countries. Sedation is one of the important issues in therapeutic endoscopy and related with reducing the failure rate. ${ }^{14,15}$ Anesthesia-administered sedation can improve the success of advanced endoscopic procedures. ${ }^{16}$ In most Western countries, ERCP is usually performed with deep sedation or general endotracheal anesthesia. In Asian countries such as Korea, ERCP is often performed under sedation by an endoscopist. A previous survey in Korea suggested that ERCP procedures were usually performed under sedation rather than general anesthesia and the most preferred agent for sedation was propofol and/or midazolam. ${ }^{8}$ Agents such as propofol, midazolam or dexmedetomidine can be used to achieve moderate sedation for the procedure. ${ }^{17}$ Previously, propofol alone provided identical or superior sedation quality than combination with midazolam in regard of both the recovery time and patient tolerance. ${ }^{18-21}$ In this survey, half of ERCP doctors in Korea preferred to use a balanced propofol sedation technique for ERCP preparation.

Post-ERCP pancreatitis is the most common complication with incidence up to $15 \%{ }^{22}$ It is sometimes severe and potentially fatal, with a mortality rate of $0.1 \%$ to $0.5 \%$. A 
number of agents or techniques have been investigated previously to prevent post-ERCP-pancreatitis. Previous metaanalyses suggested that the use of rectal nonsteroidal antiinflammatory drug, ${ }^{23-25}$ aggressive hydration with lactated Ringer's solution and prophylactic pancreatic stent placement are effective in reducing the incidence and severity of post-ERCP pancreatitis. ${ }^{26,27}$ Since rectal nonsteroidal antiinflammatory drug is not commercially available in Korea, it cannot be used for ERCP premedication as prophylaxis. In the future, more research will be needed to develop the optimal prophylactic treatment for ERCP. Since prone position ERCP is favorable with a higher technical success rate and easy to visualize an abdominal image than lateral position, ${ }^{28}$ prone position is dominantly used for patient's position during ERCP in Korea.

Among the ERCP techniques, there are important basic techniques such as selective cannulation, biliary sphincterotomy, and stone extraction. In practice, most ERCP doctors opt to cannulate the naïve papilla a sphincterotome rather than catheter. ${ }^{9}$ Generally, guidewire with a hydrophilic tip is used commonly and the use of an angled or Jtip guidewire is recommended as a standard technique. ${ }^{29}$ When performing ERCP, doctors often encounter some difficult cases such as repeated failure of selective cannulation or impacted large stones. In cases of a failed initial cannulation attempt, a salvage technique should be selected to approach the common bile duct. European Society of Gastrointestinal Endoscopy and Japan Gastroenterological Endoscopy Society recommend needle-knife fistulotomy as the salvage technique. ${ }^{30,31}$ For large common bile duct stones over $2 \mathrm{~cm}$ or impacted stones, fragmentation of the stones within the bile duct is frequently required before removal. In Korea, Trapezoid ${ }^{\mathrm{TM}}$ basket was dominantly preferred as lithotripsy device during ERCP. Most ERCP doctors choose endoscopic retrograde biliary drainage rather than endoscopic retrograde nasobiliary drainage for biliary drainage therapy. However, the advantage and effectiveness are still unclear. Thus, comparative study would be required to establish a standard biliary drainage therapy.

We found no significant differences for preferred devices or techniques between groups by doctor's experiences. The doctor's preference of basic techniques and accessories might be more closely related with the mentor's taste than the individual taste in Korea. However, this national survey in Korea has some limitations. The accuracy of the answers depended on the participants' memory, due to which recall bias could not be avoided. The lack of opinion from young doctors is another limitation of this study. The answers about ERCP environment might be inaccurate among individual doctors. National survey for all hospitals and medical centers could guarantee accurate results for
ERCP environment. Furthermore, multinational survey or prospective registry will be required to subsequent study for current trend of ERCP. Some important factors about safety such as radiation exposure, medical outcomes and complication rates are missing from the content of survey.

In conclusion, data from this survey involving ERCP doctors in Korea showed a diversity of preferences in the basic techniques and ERCP environment. More studies are required to develop ERCP standards in Korea.

\section{CONFLICTS OF INTEREST}

No potential conflict of interest relevant to this article was reported.

\section{ACKNOWLEDGEMENTS}

We thank all respondents and members of the Korean Pancreatobiliary Association for their contribution to the study.

\section{AUTHOR CONTRIBUTIONS}

Analysis and interpretation of data: J.M.L., H.K.C., T.J.S., D.W.A., Y.S.L., D.W.L. Drafting of the manuscript, statistical analysis: J.M.L. Study design, administrative, technical and material support: C.H.P., K.B.C. Critical revision of the manuscript: C.H.P., K.B.C., E.S.L., Y.N.L., H.K.C. Acquisition of data, study supervision: S.H.M., S.W.P., W.H.P., C.N.P., B.K.S., T.J.J. All authors read and approved the final manuscript.

\section{ORCID}

Jae Min Lee https://orcid.org/0000-0001-9553-5101 Sung Hoon Moon https://orcid.org/0000-0002-7879-3114 Sang Wook Park https://orcid.org/0000-0002-9556-0398 Woo Hyun Paik https://orcid.org/0000-0001-8708-3280 Chang Nyol Paik https://orcid.org/0000-0002-3470-6904 Byoung Kwan Son https://orcid.org/0000-0002-9299-5476 Tae Jun Song https://orcid.org/0000-0002-6156-8746 Dong Won Ahn https://orcid.org/0000-0002-6641-2177 Eaum Seok Lee https://orcid.org/0000-0002-5689-9567 Yun Nah Lee https://orcid.org/0000-0001-5588-784X Yoon Suk Lee https://orcid.org/0000-0002-5835-9417 Tae Joo Jeon https://orcid.org/0000-0002-8137-1633 Hyung Ku Chon https://orcid.org/0000-0002-6068-3849 
Dong Wook Lee https://orcid.org/0000-0002-1029-9064

Chang Hwan Park https://orcid.org/0000-0002-2995-8779

Kwang Bum Cho https://orcid.org/0000-0003-2203-102X

\section{REFERENCES}

1. McCune WS, Shorb PE, Moscovitz H. Endoscopic cannulation of the ampulla of Vater: a preliminary report. Ann Surg 1968;167:752-756.

2. Verma D, Gostout CJ, Petersen BT, Levy MJ, Baron TH, Adler DG. Establishing a true assessment of endoscopic competence in ERCP during training and beyond: a singleoperator learning curve for deep biliary cannulation in patients with native papillary anatomy. Gastrointest Endosc 2007;65:394-400.

3. Moffatt DC, Yu BN, Yie W, Bernstein CN. Trends in utilization of diagnostic and therapeutic ERCP and cholecystectomy over the past 25 years: a population-based study. Gastrointest Endosc 2014;79:615-622.

4. Park JM, Kang CD, Lee JC, Hwang JH, Kim J. Recent 5-year trend of endoscopic retrograde cholangiography in Korea using national health insurance review and assessment service open data. Gut Liver 2020;14:833-841.

5. Waye JD. Basic techniques of ERCP. Gastrointest Endosc 2000;51:250-253.

6. Katanuma A, Isayama H. Current status of endoscopic retrograde cholangiopancreatography in patients with surgically altered anatomy in Japan: questionnaire survey and important discussion points at Endoscopic Forum Japan 2013. Dig Endosc 2014;26 Suppl 2:109-115.

7. Yasuda I, Isayama H, Bhatia V. Current situation of endoscopic biliary cannulation and salvage techniques for difficult cases: current strategies in Japan. Dig Endosc 2016;28 Suppl 1:62-69.

8. Ahn DW, Han JH, Kim HJ, et al. Practice of endoscopic retrograde cholangiopancreatography in Korea: results from a national survey. Korean J Pancreas Biliary Tract 2019;24:2130.

9. Baron TH, Kozarek RA, Carr-Locke DL. ERCP. 3rd ed. Philadelphia: Elsevier, 2019.

10. Mulder CJ, Jacobs MA, Leicester RJ, et al. Guidelines for designing a digestive disease endoscopy unit: report of the World Endoscopy Organization. Dig Endosc 2013;25:365375.

11. Hilsden RJ, Romagnuolo J, May GR. Patterns of use of endoscopic retrograde cholangiopancreatography in a Canadian province. Can J Gastroenterol 2004;18:619-624.

12. Varadarajulu S, Kilgore ML, Wilcox CM, Eloubeidi MA. Relationship among hospital ERCP volume, length of stay, and technical outcomes. Gastrointest Endosc 2006;64:338-347.
13. Allison MC, Ramanaden DN, Fouweather MG, Davis DK, Colin-Jones DG. Provision of ERCP services and training in the United Kingdom. Endoscopy 2000;32:693-699.

14. Raymondos K, Panning B, Bachem I, Manns MP, Piepenbrock S, Meier PN. Evaluation of endoscopic retrograde cholangiopancreatography under conscious sedation and general anesthesia. Endoscopy 2002;34:721-726.

15. Thosani N, Banerjee S. Deep sedation or general anesthesia for ERCP? Dig Dis Sci 2013;58:3061-3063.

16. Buxbaum J, Roth N, Motamedi N, et al. Anesthetist-directed sedation favors success of advanced endoscopic procedures. Am J Gastroenterol 2017;112:290-296.

17. Li S, Sheng G, Teng Y, Sun M. Systematic review of anaesthetic medication for ERCP based on a network metaanalysis. Int J Surg 2018;51:56-62.

18. Wehrmann T, Kokabpick S, Lembcke B, Caspary WF, Seifert $\mathrm{H}$. Efficacy and safety of intravenous propofol sedation during routine ERCP: a prospective, controlled study. Gastrointest Endosc 1999;49:677-683.

19. Jung M, Hofmann C, Kiesslich R, Brackertz A. Improved sedation in diagnostic and therapeutic ERCP: propofol is an alternative to midazolam. Endoscopy 2000;32:233-238.

20. Riphaus A, Stergiou N, Wehrmann T. Sedation with propofol for routine ERCP in high-risk octogenarians: a randomized, controlled study. Am J Gastroenterol 2005;100:1957-1963.

21. Bo LL, Bai Y, Bian JJ, Wen PS, Li JB, Deng XM. Propofol vs traditional sedative agents for endoscopic retrograde cholangiopancreatography: a meta-analysis. World J Gastroenterol 2011;17:3538-3543.

22. ASGE Standards of Practice Committee, Anderson MA, Fisher L, et al. Complications of ERCP. Gastrointest Endosc 2012;75:467-473.

23. Williams EJ, Taylor S, Fairclough P, et al. Are we meeting the standards set for endoscopy? Results of a large-scale prospective survey of endoscopic retrograde cholangiopancreatograph practice. Gut 2007;56:821-829.

24. Zheng $\mathrm{MH}$, Xia HH, Chen YP. Rectal administration of NSAIDs in the prevention of post-ERCP pancreatitis: a complementary meta-analysis. Gut 2008;57:1632-1633.

25. Elmunzer BJ, Waljee AK, Elta GH, Taylor JR, Fehmi SM, Higgins PD. A meta-analysis of rectal NSAIDs in the prevention of post-ERCP pancreatitis. Gut 2008;57:1262-1267.

26. Wu D, Wan J, Xia L, Chen J, Zhu Y, Lu N. The efficiency of aggressive hydration with lactated ringer solution for the prevention of post-ERCP pancreatitis: a systematic review and meta-analysis. J Clin Gastroenterol 2017;51:e68-e76.

27. Mazaki T, Mado K, Masuda H, Shiono M. Prophylactic pancreatic stent placement and post-ERCP pancreatitis: an updated meta-analysis. J Gastroenterol 2014;49:343-355.

28. Mashiana HS, Jayaraj M, Mohan BP, Ohning G, Adler DG. Comparison of outcomes for supine vs. prone position 
ERCP: a systematic review and meta-analysis. Endosc Int Open 2018;6:E1296-E1301.

29. Reddy DN, Nabi Z, Lakhtakia S. How to improve cannulation rates during endoscopic retrograde cholangiopancreatography. Gastroenterology 2017;152:1275-1279.

30. Testoni PA, Mariani A, Aabakken L, et al. Papillary cannula- tion and sphincterotomy techniques at ERCP: European Society of Gastrointestinal Endoscopy (ESGE) clinical guideline. Endoscopy 2016;48:657-683.

31. Ryozawa S, Itoi T, Katanuma A, et al. Japan Gastroenterological Endoscopy Society guidelines for endoscopic sphincterotomy. Dig Endosc 2018;30:149-173. 